\title{
19. Martensitic Transformation in Cathodically Hydrogen Charged Type 316 Austenitic Stainless Steels
}

\author{
By Noboru Tsukuda and Takatoshi ARAI \\ Research Institute for Applied Mechanics, Kyushu University, \\ Kasuga, Fukuoka 816 \\ (Communicated by Ryukiti Hasiguti, M. J. A., April 12, 1993)
}

\begin{abstract}
Cathodically hydrogen charged type 316 austenitic stainless steel has been studied by $\mathrm{x}$-ray diffraction. Both $\varepsilon$ and $\alpha^{\prime}$ martensites are formed by cathodic charging in solution-treated samples, however very small amount of additional martensitic phase formation was observed in cold-worked samples. The volume fraction of $\varepsilon$ phase decreases with increasing ageing time. $\varepsilon$ and $\alpha^{\prime}$ phases revert to $\gamma$ phase below $723 \mathrm{~K}$ and $923 \mathrm{~K}$, respectively. The incorporated hydrogen induces the metastable $\varepsilon$ and $\alpha^{\prime}$ phases. The transformation is suppressed by the tangled dislocation networks introduced by cold work. $\varepsilon$ phase is more unstable, thereby it converts to $\alpha^{\prime}$ and $\gamma$ phases by hydrogen release. The hydrogen concentration in $\varepsilon$ phase is higher han that in $\gamma$ phase and that in $\alpha^{\prime}$ phase is very low. The change of the x-ray profiles during ageing comes from the change of the spatial distribution of hydrogen atoms. By fitting the observed profiles to those calculated by Fick's law, the diffusion coefficent of hydrogen has been evaluated as $1.0 \times 10^{-11} \mathrm{~cm}^{2} \mathrm{~s}^{-1}$, for both $\varepsilon$ and $\gamma$ phases.
\end{abstract}

Key words: Martensitic transformation; austenitic stainless steel; cathodic hydrogen charging; x-ray diffraction.

Introduction. Since hydrogen incorporation into steels brings the degradation, a large number of investigations on steel-hydrogen system have been performed from practical importance. Hydrogen charging is carried out by transmission in high pressure hydrogen atmosphere, quenching from high temperature, ion implantation by accelerators, or cathodic charging in electrolytic solution. In this study, the cathodic charging has been employed. The hydrogen concentration in austenitic stainless steels charged by the cathodic charging is of the order of $10 \%$. The over-saturated hydrogen induces the lattice dilatation of the matrix (fce $\gamma$ phase) and causes the martensitic transformation. It is considered to be the stress-induced phase transformation. There are two martensitic phases, one is bec $\alpha^{\prime}$ phase and another is hep $\varepsilon$ phase. ${ }^{1-4)}$

The hydrogen concentration at depth $\mathrm{x}$ introduced during $t_{c}$ implantation and aged during $t_{a}$ is:

$\mathrm{C}(\mathrm{x})=\mathrm{C}_{0} /\left(4 \pi \mathrm{D}_{\mathrm{E}} \mathrm{t}_{\mathrm{a}}\right)^{1 / 2} \int_{0}^{\infty}\left\{\exp \left[-(\mathrm{x}-\mathrm{u})^{2} / 4 \mathrm{D}_{\mathrm{E}} \mathrm{t}_{\mathrm{a}}\right]-\exp \left[-(\mathrm{x}+\mathrm{u})^{2} / 4 \mathrm{D}_{\mathrm{E}} \mathrm{t}_{\mathrm{a}}\right]\right\} \operatorname{erfc}\left[-\mathrm{u} / 2\left(\mathrm{D}_{\mathrm{I}} \mathrm{t}_{\mathrm{c}}\right)^{1 / 2}\right] \mathrm{du}$,

where $\mathrm{C}_{0}$ is the hydrogen concentration just beneath the surface, $\mathrm{D}_{\mathrm{I}}, \mathrm{D}_{\mathrm{E}}$ the diffusion coefficient for influx and efflux of hydrogen. ${ }^{5), 6)}$ Hydrogen concentration in $\gamma, \varepsilon$ and $\alpha^{\prime}$ phases decreases nonuniformly with increasing ageing time as shown in Fig. 1.

$\mathrm{X}$-ray diffraction technique is a powerful tool for the present subject. First, identification of $\varepsilon$ phase requires a diffraction technique, second, the volume fraction of these phases and the information about the lattice spacing can be obtained. X-ray diffraction studies on the diffusion coefficient of hydrogen by using single crystals ${ }^{7)}$ and polycrystals $^{8)}$ have been extensively performed. Solute hydrogen induces the lattice 


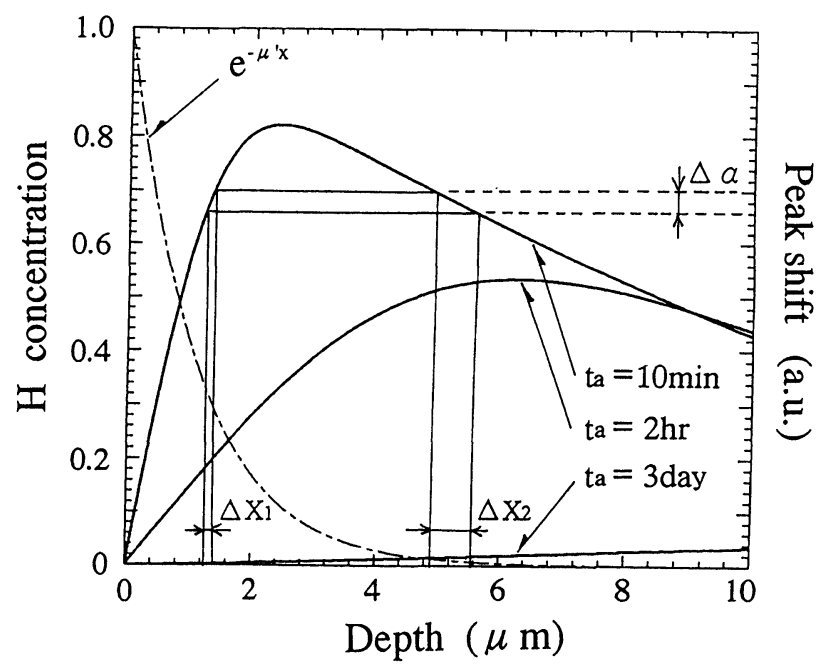

Fig. 1. Depth distribution of hydrogen $\mathrm{C}(\mathrm{x})$ and corresponding peak shift $\alpha . \mathrm{t}_{\mathrm{c}}=22 \mathrm{hr}, \mathrm{D}=1.0 \times 10^{-11} \mathrm{~cm}^{2} \mathrm{~s}^{-1}$.

dilatation $\varepsilon(\mathrm{x})$, which is represented as $\varepsilon(\mathrm{x})=\Delta \mathrm{V} / \mathrm{V}_{\mathrm{c}} \mathrm{C}(\mathrm{x}) / 3$, where $\Delta \mathrm{V}$ is the volume change by a hydrogen atom and is $0.29 \AA^{3}, \mathrm{~V}_{\mathrm{c}}$ is the mean atomic volume of the matrix atoms. ${ }^{6)} \mathrm{A}$ peak shift of a Bragg reflexion $\alpha(\mathrm{x})$ is written as: $\alpha(\mathrm{x})=-2 \varepsilon(\mathrm{x}) \tan \theta_{0}$, where $\theta_{0}$ is the Bragg angle of a regular lattice. The intensity of diffracted x-rays in the region between $\alpha$ and $\alpha+\mathrm{d} \alpha$ is proportional to the concerning volume $\mathrm{S}\left(\mathrm{dx}_{1}+\mathrm{dx}_{2}\right)$, where $\mathrm{S}$ is the irradiated area by $x$-rays. On the other hand, the intensity of diffracted $x$-rays decreases with increasing $\mathrm{x}$-ray path length by the absorption effect as $\mathrm{e}^{-\mu^{\prime} \mathrm{x}}$, where $\mu^{\prime}=\mu[1 / \sin \theta+1 / \sin (2 \theta-\omega)], \mu$ the linear absorption coefficient and $\omega$ the angle between incoming x-rays and the surface (see also Fig. 1). Consequently, an x-ray profile $\mathrm{P}_{1}(\alpha)$ is represented as:

$\mathrm{P}_{1}(\alpha) \mathrm{d} \alpha=\mathrm{K}\left[\exp \left(-\mu^{\prime} \mathrm{x}_{1}\right) \mathrm{dx}_{1}+\exp \left(-\mu^{\prime} \mathrm{x}_{2}\right) \mathrm{dx}_{2}\right]$,

where $\mathrm{K}$ is a constant, $\mathrm{x}_{1}$ and $\mathrm{x}_{2}$ are taken the region of increasing and decreasing $\mathrm{C}(\mathrm{x})$, respectively. An experimentally observable profile $\mathrm{P}(\alpha)$ is a convolution of the $\mathrm{P}_{1}(\alpha)$ and the noncompositional spectrum such as the residual size broadening and the instrumental broadening. In the present analysis, the observed profiles of the samples aged during 1 week were adopted as the noncompositional spectrum for each peak.

Experiments. Commercial type 316 austenitic stainless steel with the composition $(16-18 \% \mathrm{Cr}, 10-14 \% \mathrm{Ni}, 2-3 \% \mathrm{Mo},<2 \% \mathrm{Mn},<2 \% \mathrm{Si})$ were used for the experiments. Sheets of the material were thinned to $200 \mu \mathrm{m}$ in thickness by cold-rolling, which introduces $\alpha^{\prime}$ phase in the matrix. The dimension of the cold-worked sample is $15 \times 20 \times 0.2 \mathrm{~mm}^{3}$. Some of them were solution annealed at $1323 \mathrm{~K}$ for 1 hour and quenched to room temperature and used as solution treated samples. $\alpha^{\prime}$ phase was removed by the treatment. Hydrogen cathodic charging was carried out with the current of 10 and $100 \mathrm{~mA} / \mathrm{cm}^{2}$ in the aqueous solution of $1 \mathrm{~N} \mathrm{H}_{2} \mathrm{SO}_{4}+0.25 \mathrm{~g} / \mathrm{NaAsO} \mathrm{N}_{2}$. The charging time $t_{c}$ was 22 hours.

After hydrogen charging, succesive x-ray diffraction measurements were carried out. Monochromatized $\mathrm{Cr} \mathrm{K} \alpha$ radiation was employed using a RIGAKU RU-300 x-ray generator. The operating condition was $50 \mathrm{kV}$ and $200 \mathrm{~mA}$. The measurement time was 500 and 1000 sec. A position sensitive detector was used to make simultaneous measurements for the whole region of interest angle. The samples were rotated on the normal axis of the surface for averaging the intensitiy from each grain. The glancing angle $\omega$ was 9 degree.

The isochronal annealing experiments were also performed for examining the stability 
of the martensitic phases up to $1023 \mathrm{~K}$. The annealing time was 1 hour.

Results. X-ray profiles of type 316 stainless steel before and after hydrogen charging are shown in Figs. 2(a) and (b). New peaks of $\varepsilon$ and $\alpha^{\prime}$ phases were observed by hydrogen charging in solution-treated samples. However, very small amount of $\varepsilon$ phase and additional $\alpha^{\prime}$ phase were observed in cold-worked samples. The intesitiy of $\varepsilon$ peak decreases and that of $\alpha^{\prime}$ increases with increaing ageing time. While the shape of $(100)_{\alpha}$ peak is constant during ageing, the peaks of $(111)_{\gamma}$ (identical to $\left.(00.2)_{\varepsilon}\right),(200)_{\gamma},(10.0)_{\varepsilon}$ and $(10.1)_{\varepsilon}$ are broader than those of uncharged $\gamma$ phase and their peak positions shift to lower angles. They become sharp and turn to the regular positions. In the early stage of ageing, very broad tails were observed. They becomes small with increasing ageing time. Even after ageing during 3 days, all the profiles are broader than those of uncharged samples and profiles of $(110)_{\gamma}$ and $(10.1)_{\varepsilon}$ are broader than those of (111) $\gamma$.

As shown in Fig. 3, $\varepsilon$ and $\alpha^{\prime}$ phases revert to $\gamma$ phase below $723 \mathrm{~K}$ and $923 \mathrm{~K}$, respectively.

If the hydrogen distribution is represented by the form in eq. (1), the diffusion coefficient of hydrogen can be evaluated by fitting calculated profiles to the observed profiles as shown in Fig. 4. The evaluated values of $\mathrm{D}_{\mathrm{E}}$ for $\gamma$ and $\varepsilon$ phases are almost same and is $1.0 \times 10^{-11} \mathrm{~cm}^{2} \mathrm{~s}^{-1}$.

Discussion. The mechanism of $\gamma \rightarrow \varepsilon$ transformation is not well established. As a possible model, $\varepsilon$ phase may be formed by the motion of the Schockley partial dislocations on $\{111\}_{\gamma}$ plane, which form stacking faults. Hydrogen may effect the decreasing of the stacking fault energy. However, the detailed understanding, if the effect is originated by the chemical effect (hydride) and/or the stress effect, is not known. The motion of the Schockley partial dislocations may be impeded by the dislocations introduced by cold work thereby the martensitic transformation may be suppressed. Very small amount of

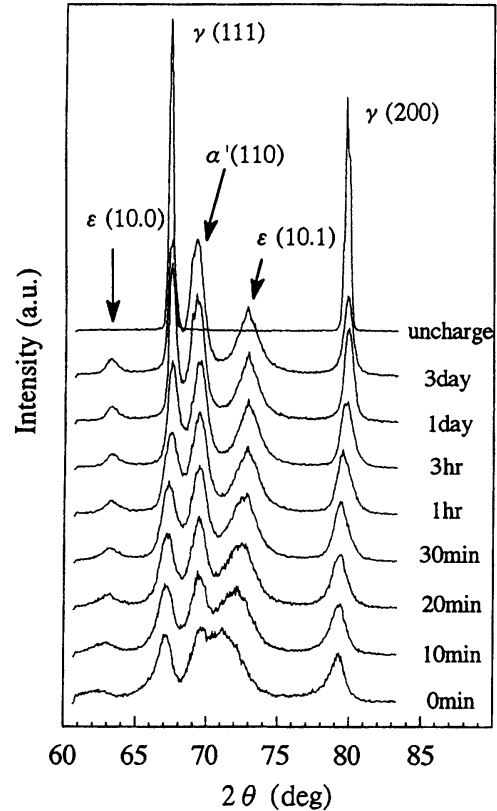

(a)

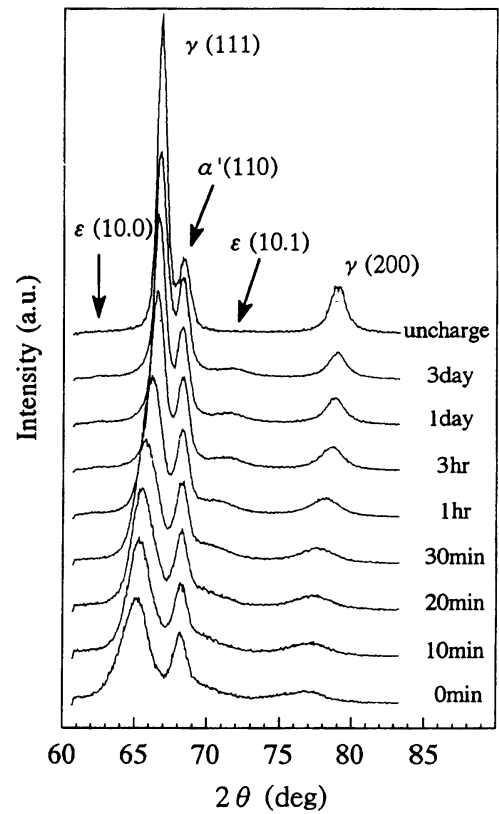

(b)

Fig. 2. X-ray profiles of before and after hydrogen charged type 316 stainless steel. (a): solution-treated, (b) cold-worked samples. $t_{c}=22 \mathrm{hr}$. 
[Vol. 69(B),

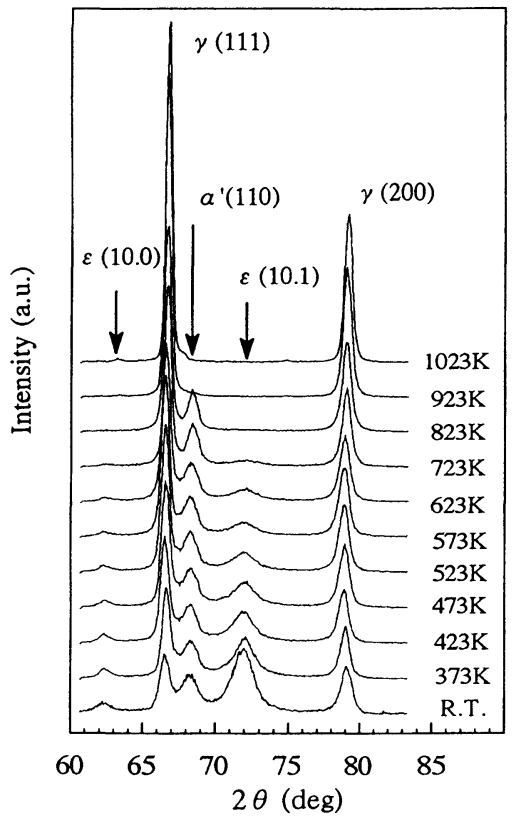

Fig. 3. X-ray profiles of solution-treated samples annealed at various temperatures.

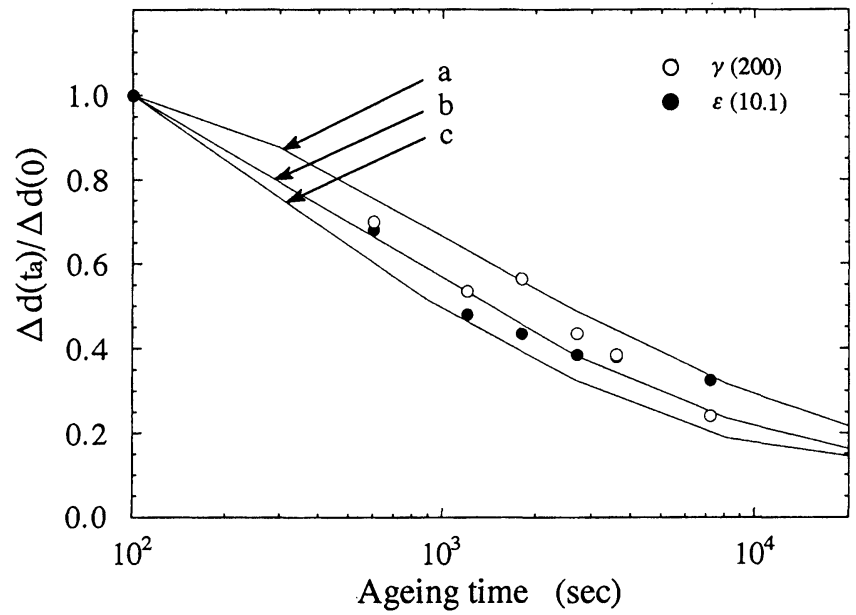

Fig. 4. Recovery of $\mathrm{d}$-spacing during ageing. $\Delta \mathrm{d}(0) / \mathrm{d}=0.021$ for $(10.0)_{\varepsilon}$, $\Delta \mathrm{d}(0) / \mathrm{d}=0.012$ for $(200)_{\gamma}$ a: $\mathrm{D}=2.0 \times 10^{-11} \mathrm{~cm}^{2} \mathrm{~s}^{-1}, \mathrm{~b}: 1.0 \times 10^{-11} \mathrm{~cm}^{2} \mathrm{~s}^{-1}$, c: $0.5 \times 10^{-11} \mathrm{~cm}^{2} \mathrm{~s}^{-1}$.

additional martensitic phase in cold-worked samples may be understood by this mechanism.

$\varepsilon$ and $\alpha^{\prime}$ phases are metastable and revert to $\gamma$ phase by elevated temperature annealing. The formation and the stability of $\varepsilon$ phase depends on the stacking fault energy and those of $\alpha^{\prime}$ depends on the composition of $\mathrm{Cr}$ and $\mathrm{Ni}$. It is well known that the activation enthalpy of $\gamma \rightarrow \varepsilon$ transformation is much smaller and only a few percent of that of 
$\gamma \rightarrow \alpha^{\prime}$ transformation. This is a reason that the lower $A_{S}$ temperature of $\varepsilon \rightarrow \gamma$ than that of $\alpha^{\prime} \rightarrow \gamma$.

The solubility of hydrogen in $\alpha$ iron is much smaller than that in austenitic stainless steels and the diffusion coefficient of hydrogen in $\alpha$ iron is much larger than that of austenitic stainless steels. Therefore, the stable profiles of $(110)_{\alpha}$ are resulted from the low concentration of hydrogen in $\alpha^{\prime}$ phase. Much broader profiles and larger peak shift of $\varepsilon$ phase than those of $\gamma$ phase are caused by the higher hydrogen concentration in $\varepsilon$ phase, which is understood that $\varepsilon$ phase is formed preferentially at the region of higher hydrogen concentration. In polycrystalline materials grain boundaries act as hydrogen paths and sinks. In this case, the apparent diffusion may be larger than bulk diffusion. It depends on the grain size distribution. As a result, nonuniform hydrogen distribution comes from not only the bulk diffusion represented in eq. (1) but also the microstructure such as grains boundaries, dislocations, cracks and internal strain.

The extra tails in the profiles of the early stage of ageing can not be explained by the concentration profile of hydrogens and the size effect. They may be the distortion broadening caused by hydrogens and/or the diffuse scattering by the stacking disorder on $\{111\}_{\gamma}$.

Acknowledgements. The authors wish to thank emeritus Prof. R. Hasiguti, M. J. A., in University of Tokyo and Prof. E. Kuramoto in Kyushu University for the valuable discussion.

\section{References}

1) Holzworth, M. L., and Louthan, M. R., Jr.: Corrosion, 24, 110-124 (1968).

2) Narita, N., Altstetter, C. J., and Birnbaum, H. K.: Met. Trans., 13A, 1355-1365 (1982).

3) Rozenak, P., and Eliezer, D.: J. Mat. Sci., 19, 3873-3879 (1984).

4) —: Acta Metall., 35, 2329-2340 (1987).

5) Carslaw, H. S., and Jaeger, J. C.: Conduction of Heat in Solids. Oxford Clarendon Press (1959).

6) Baranowski, B., Majchrzak, S., and Flanagan, T. B.: J. Phys., F1, 258 (1971).

7) Ulmer, D. G., and Altstetter, C. J.: J. Mat. Res., 2, 305-312 (1987).

8) Zevin, L. S., and Melamed, Z.: J. Appl. Cryst., 18, 267-271 (1985). 